ARID International Journal of Social Sciences and Humanities (AIJSSH) VOL.4, NO.7, January 2022

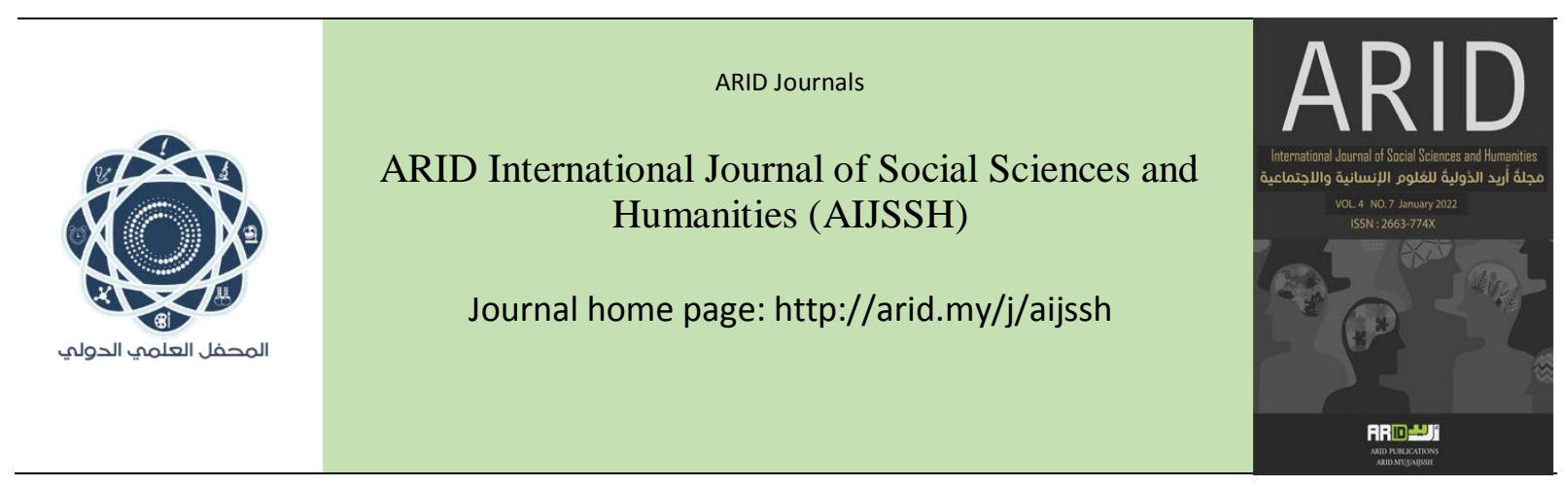

$$
\begin{aligned}
& \text { مَجلةُ أُريد الدَّوليُُّ للعُلومِ الإنسانية والإجتماعية } \\
& \text { العدد السابع، البجلد الرابع، كانون الثاني } 2022 \text { م }
\end{aligned}
$$

\title{
Investing in renewable energies as a strategic option to advance sustainable development in Algeria
}

\author{
الاستثمار في الطاقات المتجدة كخيار استراتيجي لدفع عجلة التنمية المستدامة في الجزائر

$$
\text { جامعة جيلالي ليابس سيدي بلعباس، الجزائر }
$$ \\ بكاري مختار \\ جامعة مصطفى اسطمبولي معسكر، الجزائر
}




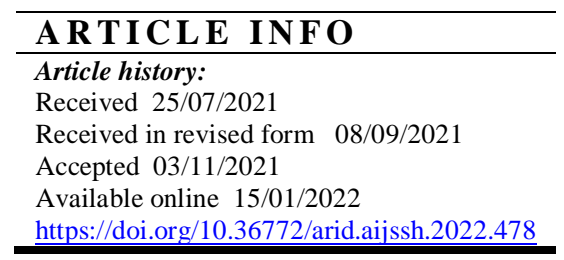

\begin{abstract}
This paper aims to highlight the importance of investing in renewable energies in order to advance sustainable development in Algeria, as investment in this field has known continuous development in recent years, convinced that renewable energies are the most important and strategic option for achieving sustainable development in the future, and has been reached To a set of results, the most important of which are that renewable energy has the ability to meet the need for development in Algeria, as well as its ability to increase development and growth on a large scale, and renewable energy plays an important role in translating the dimensions of sustainable development, as its development projects contribute to achieving Economic gains, improve social conditions and preserve the environmental heritage for future generations, in order to achieve sustainable development.
\end{abstract}

Keywords: renewable energy, renewable energy sources, solar energy, fossil energy, sustainable development. 


\section{الملخص}

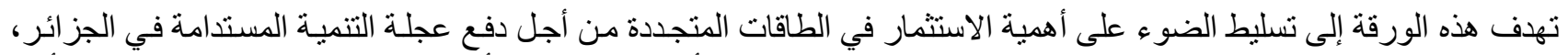

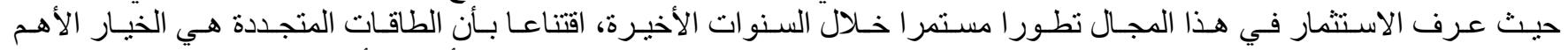

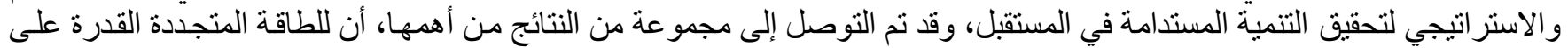

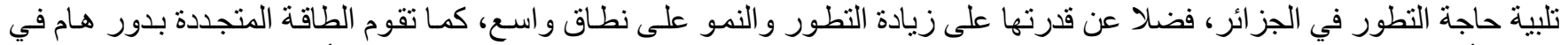

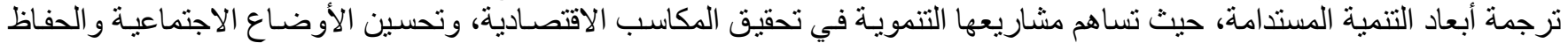
على الموروث البيئي للأجيال القادمة، بهدف تحقيق التئن التنمية المستدأمة.

الكلمات المفتاحية: الطاقة المتجددة، مصادر الطاقة المتجددة، الطاقة الثمسية، الطاقة الأحفورية، التنمية المستدامة. 
تتوجه الجزائر في السنوات الأخيرة بقوة نحو تكثيف الاستتمار ات في الطاقات المتجددة، استعدادا للخول عهد جديد من الطاقـة النظيفة بعد سنو ات طويلة من الاعتماد على المصادر التقليدية التي أصبحت مثار قلق حماة البيئة و المنظمات الدولية التي تكافح من أجل كوكب خال من آثار مدمرة، بدأت تلوح في الأفق بسبب التغيرات المناخية التي تطال مختلف دول العالم. و إيمانا منها بأهمية الطاقات البديلة والتزامها بالاتفاقيات الدولية للمحافظة على المناخ ومو اجهة التغيرات المضرة بكوكب الأرض، بدأت الجز ائر تنفيذ برنامج واعد لإنتاج الكهرباء و الوقود الحيوي باستعمال تكنولوجيا الطاقات المتجددة، حيث تعكف فرق بحث متخصصـة على إعداد مخططات وبر امج واعدة قد تبدأ نتائجها في الظهور بين سنتي 2020 و 2030 ، حيث تر اهن الجز ائر على تغطية جزء هام من الطلب الوطني على الكهرباء من الطاقات المتجددة.

ونتوفر الجزائر على إمكانات هائلة قد تجعلها رائدة في إنتاج الطاقة النظيفة، فهي تملك الصحاري الواسعة والطاقة الثمسية والرياح و المياه وكلها عو امل مساعدة على تطوير البحوث و الانتقال الناجح نحو الطاقات المتجددة والاقتصاد البديل. وبناء على ذلك يمكن صياغة إثكالية هذا البحث في السؤال الرئيسي التالي: كيف يمكن للاستثمار في الطاقات المتجددة أن يساهم في دفع عجلة التنمية المستدامة في الجزائر؟ من خلال هذه الإشكالية يمكن طرح التساؤلات الفرعية التاليــة:

$$
\text { ما هو واقع الطاقات المتجددة في الجزائر؟ }
$$

ما مدى مساهمة الطاقات المتجددة في تحقيق التنمية المستدامة؟

بغرض الإلمام بجو انب الموضوع و الإجابة على الأسئلة المطروحة في الإشكالية، تم وضـع الفرضيات المناسبة لهذا الغرض و التي تم صياغتها كالآتي: تحقيق التنمية المستدامة يتطلب الاستثمار في الطاقات المتجددة. تتـو افر الجز ائر على مصـادر مهمـة مـن الطاقـة المتجددة ممـا يجعلهـا تخـوض تجربـة التحول مـن الطاقـة التقليديـة إلـي الطاقـة 
-إبراز دور الطاقة المتجدة وأهميتها في تحقيق التتمية المستدامة بدون الإضرار بالبيئة وكذلك أهمية تحفيز الاستثمارات في مجال الطاقة المتجددة.

-زيادة الطلب على الطاقة لتحقيق أهداف التنمية مع الحد من استخدام الطاقة التقليدية. أهداف الدراسة: تهذف هذه الدراسة إلى:

ــفع عملية البحث وتطوير الطاقة المتجددة من خلال إبراز حجم المخاطر البيئية التي تواجه البشرية. ـايجاد سبل واستر اتيجيات قوية للتحول إلى اقتصاديات الطاقة المتجدة في الجزائر وتشجيع الاستثمار في هذا المجال. منهج الاراسة: قصد تحقيق الأهداف المحددة تم الاعتماد على المنهج الوصفي التحليلي الذي يتلاءم و هدا النوع من البحوث، التي تقوم على جمع الحقائق والبيانات الكمية أو الكيفية عن الظاهرة المراد دراستها، ومحاولة تفسير هذه الحقائق تفسير ا كافيا خدمة للموضوع.

\section{مصطحات البحث:}

ـالطاقات المتجددة: تتشكل الطاقة المتجددة من مصادر الطاقة الناتجة عن مسار ات الطبيعة التلقائية كأثقعة الثمس و الرياح و التي تتجدد في الطبيعة بوتبرة أعلى من وتيرة استهلاكها.

ـالتنمية المستدامة: هي التنمية التي تلبي احتياجات الحاضر من دون المساومة بقدرة الأجيال المقبلة علي تلبية احتياجاتها. مصادر الطاقة المتجددة: هي عبارة عن مصادر طبيعية دائمة وغير ناضبة ومتوفرة في الطبيعة سواء كانت محدودة أو غير محدودة ولكنها متجددة باستمرار و هي نظيفة لا ينتج عنها أي نلوث بيئي. الار اسات السابقة:

الدراسة الأولى: در اسة قام بها محمد طالبي، محمد ساحل (2008)، بعنوان " أهمية الطاقة المتجدة في حماية البيئة لأجل التنمية المستدامة، عرض تجربة ألمانيا" وتهدف هذه الدر اسة إلى بلورة حقيقة أهمية الطاقة المتجدة لأجل التنمية المستدامة، والتعرف على تجربة ألمانيا في هذا المجال والتي يمكن أن تستفيد منها العديد من دول العالم النامي ومنها الدول العربية، وقد خلصت هذه الدراسة إلى 
ـ للطاقة المتجدد أهمية بالغة في حماية البيئة باعتبار ها طاقة نظيفة غير ملوثة، كما أن التوسع في استخدامها من شأنه أن يقلص من استخدام الطاقة التقليدية المعروفة بأثر ها السيئ على البيئة، خاصة و أن كلفة توليد الكهرباء من الطاقة المتجددة آخذة في النقصان ومنه إمكانية تحقيق تنمية مستدامة.

ـ في ظل تعقد مشكلة البيئة في ألمانيا، تسعى الحكومة الألمانية لحل هذه المشكلات باللجوء إلى الطاقة المتجددة، خصوصـا أن ألمانيا تشهد ازدهار ا كبير ا في مجال الطاقة المتجدةة، ومنه التقليل من استخدام الطاقة التقليدية والحدّ من انبعاث الغازات الضارة من الكربون و النيترو جين و الكبريت.

الدر اسة الثانية: در اسة قام بها حاج موسى أحمد (2014)، "بعنوان الطاقة الناضبة وعلاقتها بالتنمية المستدامة" دراسة حالة الجزائر، تناولت الدراسة زيادة الوعي بترشيد الطاقة وأهميتها في إطالة عمر الوقود الأحفوري، ومعرفة مكانة قطاع الطاقة المستدامة و الطاقة الناضبة في الاقتصاد الجزائري.

وقد نوصل إلى النتائج التالية، أداء الاقتصاد الوطني لا يز ال مرتبطا بدرجة كبيرة بقطاع المحروقات وهو المصدر الوحيد للطاقة، كما أن تطبيق التنمية المستدامة يؤدي إلى الوصول إلى ما يعرف بالعدالة الاقتصادية، و الطاقة المتجددة على الرغم من التحديات التي تواجهها إلا أنها تعد مصدر ا مستقبليا للطاقة.

الدراسة الثالثة: دراسة قام بها الجهاز المركزي للتعبئة العامة والإحصاء في جمهورية مصر العربية (2015)، بعنوان "دراسة مستقبل الطاقة الثمسية في مصر"، وكانت أهم نتائج الدراسة، وضع الدولة لعدد من المشاريع المستقبلية التي تسعى لاستغلال الطاقة الثمسية وإحلالها محل الطاقة غير المتجدة، ومن تلك المشاريع و التي تهدف إلى زيادة ما تسهم به الطاقة الثمسية في توفير احتباجات مصر من الكهرباء النظيفة والحد من الاعتماد على الوقود التقليدي في توليد الكهرباء، والخطة الخماسية للطاقة الثمسية (2016/20152017/2016) ، تهدف إلى إنشاء محطة شمسية حرارية لتوليد الكهرباء بقدرة إجمالية 100 ميغاوات، أما الخطة الثانية هي الخطة التنفيذية (2026/2025-2017/2016) و التي تهدف للوصول بالقدرات المركبة من الطاقة الثمسية إلى 3000 ميغاو ات خلال الفترة المقررة للمشروع.

الدراسة الرابعة: در اسة قامت بها فريدة كافي (2016)، بعنوان الطاقات المتجددة بين تحديات الواقع ومأمول المستقبل: التجربة الألمانية نموذجا، و اتبعت، وقد تناولت التأصيل النظري للطاقات، الوضع العالمي للطاقات المتجددة واقتصاداتها، التحديات والعوامل التي تو اجه نمو الطاقة المتجدة و انتشار هاو عرض التجربة الر ائدة في مجال الطاقة المتجدة " ألمانيا"، وتوصلت الدراسة إلى النتائج 
التالية: اللجوء إلى الطاقة المتجددة هو الحل الأمثل للمزاوجة بين الأهداف الاقتصادية والبيئية، التوسع في استخدام الطاقة الأحفوري يعرقل نمو الطاقة المتجددة.

\section{مقارنة الدراسات السابقة مع الدراسة الحالية:}

بالنسبة للدر اسة الأولى فإنها تهدف إلى بلورة حقيقة أهمية الطاقة المتجددة لأجل التنمية المستدامة، والتعرف علي تجربة ألمانيا في هذا المجال، أما الدراسة الحالية فقد أعطت أهمية للاستثمار في الطاقات المتجدة من خلال عرض واقع و إمكانيات الكبيرة للجزائر التي تملكها، للاستثمار في الطاقات المتجددة لما لها من إسقاطات إيجابية على التنمية المستدامة. -بالنسبة للار اسة الثانية فتناولت التعريف بمصطلح التنمية المستدامة التي أصبح العالم ينادي بضرورة تحقيقها، ومعرفة الدور الذي يمكن أن تلعبه الطاقة المتجددة في تحقيق التنمية المستدامة، أما الدراسة الحالية فقد أولت أهمية إلى الاستثمار في الطاقات المتجددة، خصوصا الاستثمار ات في مجال الطاقة الثمسية والهوائية والمائية والتحديات التي تواجه الجز ائر مستقبلا خاصة في مجال البيئة وتغير المناخ والاحتباس الحراري، الذي أصبح يمثل خطرا على العالم وبخاصة على الجزائر لما لها من انعكاسات سلبية على التنمية المستدامة.

-بالنسبة للار اسة الثالثة اهتمت بزيادة الوعي بترشيد الطاقة وأهميتها في إطالة عمر الوقود الأحفوري، ومعرفة مكانة قطاع الطاقة المستدامة والطاقة الناضبة في الاقتصاد الجزائري، على عكس الدراسة الحالية التي تسعى إلى التوجه نحو الطاقات المتجددة والنظيفة و الصديقة للبيئة من خلال الاستثمار والتنويع الاقتصادي في مجال الطاقة. -بالنسبة للدر اسة الرابعة فقد ركزت هذه الدر اسة على مستقبل الطاقة الشمسية في مصر، أما الدراسة الحالية فقد أكدت على الاستدامة للطاقات المتجدة في الجزائر من خلال الاستثمار في جميع الاستخدامات المختلفة للموارد الطاقوية بهدف تحقيق أكبر قدر من الفاعلية والاستدامة و الإنصاف.

بالنسبة للدر اسة الخامسة تناولت التأصيل النظري للطاقات، و الوضع العالمي للطاقات المتجددة واقتصاداتها، التحديات والعو امل التي تواجه نمو الطاقة المتجدةة وانتشار ها وعرض التجربة الر ائدة في مجال الطاقة المتجددة " ألمانيا"، أما الدراسة الحالية فقد ركزت على عرض واقع الطاقات المتجدة في الجز ائر و التي تعد في بدايتها من خلال الاستثمار الذي يعد خيارا استراتجيا لتحقيق تتمية مستدامة، تتطلب تضافر جميع الجهود في استخدام مصادر الطاقة المتجددة وذلك عبر اعتماد السياسات والتشريعات المناسبة واتخاذ الإجر اءات التقنية الضرورية، وتصميم إطار جاذب للاستثمار وتعديل هيكل أسعار الطاقة المتجدة و إنشاء نافذة استثمارية خاص بمشاريع الطاقة المتجددة، وإثر الك القطاع الخاص و العام في تنفيذ مشاريع الطاقة المتجددة و التدريب و التأهيل والتشبيك في مجال الطاقة المتجددة ودعم أبحاث الطاقة المتجددة. 
وبغية الإلمام بعناصر هذا الموضوع، تم تقسيم هذه الدراسة إلى المحاور التالية:

" التأصيل النظري للطاقة المتجددة والتنمية المستدامة.

• واقع الطاقات المتجددة في الجزائر.

• الاستثمار في البرنامج الوطني للطاقات المتجددة.

المبحث الأول: التأصيل النظري للطاقة المتجددة والتنمية المستدامة.

1- 2 - مفهوم الطاقة المتجددة:

الطاقة المتجدة هي الطاقة المستمدة من الموارد الطبيعية التي تتجدد أي التي لا تنفذ، تختلف جو هريا عن الوقود الأحفوري من البترول و الفحم و الغاز الطبيعي لذلك يمكن تعريف الطاقة المتجددة بأنها تللك المو ارد التي نحصل عليها من خلال تيار ات الطاقة التي يتكرر وجودها في الطبيعية على نحو تلقائي ودوري.

و أيضا الطاقة المتجددة هي عبارة عن مصادر طبيعية دائمة وغير ناضبة ومتوفرة في الطبيعية سو اء كانت محدودة أو غير محدودة ولكنها متجددة باستمر ار، وهي نظيفة لا ينتج عنها تلوث بيئي نسبيا.

11

تعريف وكالة الطاقة العالمية (IEA): تتشكل الطاقة المتجددة من مصادر الطاقة الناتجة عن مسار ات الطبيعة التلقائية كأثعة الثمس و الرياح و التي تتجدد في الطبيعة بوتيرة أعلى من وتيرة استهلاكها.

تعريف الهيئة الحكومية الدولية المعنية بتغير المناخ (IPCC): الطاقة المتجدة هي كل طاقة يكون مصدر ها شمس، جيوفيزيائي أو بيولوجي والتي تتجدد في الطبيعة بوتيرة معادلة أو أكبر من نسب استعمالها، وتتولا من التيارات المتنالية والمتو اصلة في الطبيعة كطاقة الكتلة الحيوية، الطاقة الثمسية، طاقة باطن الأرض حركة المياه، طاقة المد والجزر في المحيطات وطاقة الرياح، ونوجد العديد من الآليات التي تسمح بتحويل هذه المصادر إلى طاقات أولية كالحرارة والطاقة الكهرومائية و إلى طاقة حركية باستخدام تكنولوجيا متعددة تسمح بتوفير خدمات الطاقة من وقود وكهرباء[1] [ تعريف برنامج الأمم المتحدة للحماية البيئة (UNEB) : الطاقة المتجددة عبارة عن طاقة لا يكون مصدر ها مخزون ثابت ومحدود في الطبيعة، تتجدد بصفة دورية أسرع من وتيرة استهلاكها وتظهر في الأشكال الخمسة التالية: الكتلة الحيوية، أشعة الثمس، الرياح، الطاقة

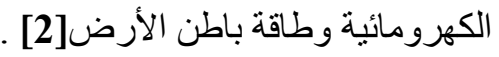




\section{1}

مصادر الطاقة المتجددة هي عبارة عن مصادر طبيعية دائمة وغير ناضبة ومتوفرة في الطبيعة سو اء كانت محدودة أو غير محدودة ولكنها متجددة باستمر ار و هي نظيفة لا ينتج عنها أب تلوث بيئي ومن أهم هذه المصادر:

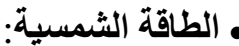

طاقة الثمس أو الطاقة الثمسية هي أهم مصدر للطاقة الحر ارية والتي يتم تحويلها إلى طاقه كهربائية، ويمكن اللجوء إلى الطاقة الثمسية في محطات توليد الكهرباء ليتم استخدامها في الحصول على بخار ماء يعمل على تشغيل تربينات توليد الكهرباء، ومن التطبيقات الثائعة لأشعة الشمس السخانات الثمسية المستخدمة في تسخين المياه بالمنازل بدلا من تللك السخانات التي تعمل بالغاز الطبيعي[3] ـ يمكن نشر الطاقة الثمسية على نطاق المرافق، حيث تقوم آلاف الصفائف من الألو اح الثمسية أو المر ايا بتغذية الكهرباء إلى الثبكة، أو على نطاق ضيق تقوم تركيبات صغيرة مثبتة على السطح بتوفير الكهرباء والمياه الساخنة لمنزل فردي، ويمكن أن توفر أنظمة الطاقة الثمسية المنزلية هذه ما يكفي من الطاقة لتشغيل الإنارة المنزلية وتشغيل الثناجة أو غير ها من السلع الكهربائية، و إعادة شحن الهواتف الجو الة، كما أن هنالك طرق مختلفة لاستغلال الطاقة الثمسية منها:

• التدفئة الشمسية: استخدام حرارة الشمس لتسخين المياه أو استخدام مواد معينة لتسخين أو تبريد المباني، ويمكن أن تستخدم هذه العملية أيضا لتحلية المياه المالحة ومعالجة مياه الصرف الصحي، ويمكن أن تستخدم الطاقة الثمسية أيضا لتوفير الطاقة الكهربائية لآلة الطبخ ومو اقد الطهي في المنازل. • الطاقة الثمسية: تحويل الطاقة الشمسية إلى كهرباء بأحد الوسيلتين: • الطاقة الثمسية المركزة (CSP) حيث تستخدم المرايا لتركيز الطاقة الثمسية من أجل توليد الحرارة لغلي الماء ودفع التوربينات البخارية وتوليد الكهرباء. • الفولطا ضوئية (PV) حيث تحول خلايا أو ألو اح الضوء مباثرة إلى كهرباء، وهذا النوع من الطاقة الثمسية شائع أيضا في تطوير الكهرباء على نطاق صغير، لتزويد الثبكات الصغيرة والمنازل الفردية. تقليديا كان هناك تحديان منعا التوسع في استغلال الطاقة

أو لا كانت وحدات الفولطا الضوئية الجاهزة المتاحة في السوق في وقت مبكر حساسة للعو امل المناخية المحلية، مثل درجات الحرارة القصوى، ومستوى الرطوبة و الرمال و التي يمكن أن تقلل من إنتاجها من الطاقة، إن التقدم التقني الحديث في تصميم الألواح الثمسية

$$
\text { الأكثر مرونة يعني أن الوحدات يمكن أن تبقى فعالة حتى في الظروف الصعبة. }
$$


ثانياـ كانت تكلفة توليد الكهرباء من الألو اح الثمسية خلال المر احل الأولى من التنمية الثمسية أعلى بكثير من الأشكال الأخرى من الطاقة، غير أن التحسينات التقنية على مدى العقد الماضي خفضت التكلفة بدرجة كبيرة، بحيث أصبح تطوير محطات توليد الطاقة الثمسية الفولطا ضوئية على نطاق واسع مجديا ويجر ي تتفيذها، وتتفوق بالفعل طاقة الرياح و الطاقة الثمسية على مستوى المرفق العام في المنافسة من حيث السعر على الوقود الأحفوري في بعض البلدان وبحلول يمكن أن تكون الطاقة الثمسية على مستوى المرفق العام أرخص من الطاقة التي تعمل بالغاز في جميع الأسواق الرئيسية في جميع أنحاء العالم، بما في ذلك الصين و ألمانيا والهند وروسيا و المملكة المتحدة و الو لايات المتحدة[4 ] .

\section{م طاقة المياه:}

تعتبر المياه مصدر الطاقة المتجدد والناضج والأكثر شيو عا إلى درجة كبيرة، وقد تم استخدام المياه لقرون لتوليد الطاقة، ويقوم أكثر من 150بلدا 77 في المئة بتوليد قدر من الكهرباء من الطاقة المائية، وتمثل 16 في المئة من الطاقة المولدة عالمبا، تتنج الطاقة المائية الحد الأدنى من انبعاثات ثاني أكسيد الكربون وبتوفر مصدر كاف من الماء يمكن أن تضمن مصدرا مستمر التوليد الكهرباء، أما إذا لم يتم تطوير ها بطريقة حساسة بيئيا، فإن الكهرباء المولدة من المياه بيكن أن تؤدي إلى اختلال بيئي كبير ، وتكاليف اجتماعية و اقتصادية من خلال البناء و إزاحتها من الخزانات وخاصة عندما لا يتم التخطبط لهذه المشاريع بشكل جيد. كما تتعدد مصادر الحصول على الطاقة من المياه حيث يمكن توليدها من المصادر التالية: ـ توليد الطاقة من التيار النهري: يتم توليد الطاقة بجعل مياه النهر المتدفقة بشكل كاف تدير توربينات تقوم بنوليد الكهرباء دون بناء سدود. ـ السدود: يتم تخزين المياه من نهر أو مصدر آخر في سد، ويتم توليد الكهرباء عندما يتم استخدام المياه من السد لدفع التوربينات. الطاقة المائية على نطاق صغير والنطاق بالغ الصغر: إن التكنولوجيا التي تستخدم تقليديا لتوليد الكهرباء على نطاق واسع يمكن أن تستخدم أيضا على نطاق أصغر بكثير، ويمكن في كثير من الأحيان استخدام "مايكرو ـ المائية" لتوفير الكهرباء للمجتمعات التي ليست قريبة من شبكة الكهرباء.

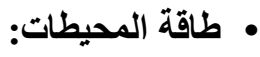
كان من المعروف على مدى عقود بأنه من الناحية النظرية يمكن استثمار الطاقة الحركية الناجمة عن حركة المحبطات لتوليد الكهرباء، ولا يز ال هذا الثكل من أثكال الطاقة المتجددة إلى حد كبير في مرحلة تجرييية ولكن له إمكانية كامنة، وهنالك طريقتان رئيسيتان لتوليد الكهرباء من المحيطات: 
ـ إن تقنيات تيار المد والجزر ممانلة لتقنيات نوليد الطاقة الكهرومائية من التيار النهري، ولكن باستخدام مياه المحيطات، توضع

$$
\text { التوربينات في موقع حيث سيتدفق المد عبره بشكل طبيعي لتوليد الكهرباء. }
$$

- يشبه الحجز المد جزري السدود المائية التقليدية، يتم حجز مياه المد القادمة ويتم نوليد الكهرباء عندما يدخل هذا الماء أو يتم إطلاقه من الحجز ، و على الرغم من الاعتر اف بأنه مصدر محتمل للطاقة وتوليد الكهرباء في الجزء المبكر من القرن العشرين، كانت طاقة المد و الجزر محدودة بسبب ارتفاع تكلفة الإنتاج ومحدودية المواقع، ويجري حالبا تجريب طرق جديدة لتوسيع جدوى هذا الأسلوب.

ـ طاقة الموج: تحتوي الموجات على كميات كبيرة من الطاقة غير المستغلة ومع ذلك كان استغلال تللك الطاقة تحديا تقنيا، و هناك عدد من الطرف لتحويل طاقة الموج إلى كهرباء، بما في ذلك استخدام المكابس التي ينم وضعها بشكل عمودي على الأمو اج، و النظم التي تستخدم موجات تتأرجح لدفع المياه عبر توربينات لتوليد الكهرباء.

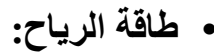

هي الطاقة الهو ائية وهي استخدام الرياح في تحويل الطاقة الحركية إلى طاقة كهربائية والنمط الثائع لطاقة الرياح هو استخدام المراوح التي تعمل كمحركات تدير توربينات هذه المر اوح المعروفة باسم (طو احين الهواء ) ولا تقتصر مهام توربينات الرياح على إنتاج الكهرباء و إنما تستخدم في تطبيقات أخرى عديدة مثل ضخ المياه وفي ري الأر اضي الزراعية وفي تسخين المياه، ومراوح الهواء هذه التي تتتج الطاقة يمكن بنائها في غضون أسابيع مما يجعلها مصدر فعّال وسريع لإنتاج الطاقة، ولكن من الصعوبات التي تو اجه توليد الطاقة بو اسطة الرياح هي أن الرياح مصدر ها متذبذب لطاقة متذبذبة، حيث لا يتو افر الهواء السريع طو ال العام بأكمله، فهنالك أوقات من الرياح القوية و هنالك أوقات من الهو اء الساكن، لذلك لا يمكن الاعتماد عليها كمصدر ثابت للحصول على الطاقة.

وقد استثرت بعض الدول بكثافة في استخدام طاقة الرياح، تنتج الدانمارك الآن على سبيل المثنال 35 في المئة من احتياجاتها من الكهرباء من توربينات الرياح ويتمثل أحد تحديات طاقة الرياح في أنها ليست مصدر ا مستقر التوليد الكهرباء، إذ يختلف المعدل اعتمادا على قوة الرياح لتحريك التوربينات في أي وقت من الأوقات، يمكن أن تكون الرياح عنصر ا قيما في خطة أوسع نطاقا لتوليد الكهرباء و غالبا ما تقارن مع غير ها من مصادر الطاقة المتجددة.

و هنالك تحد آخر أثثر مؤخر الطاقة الرياح يتعلق بالمخاوف التي أبداها السكان الذين يقيمون بالقرب من نوربينات الرياح، ومع ذلك، فإن وتيرة توليد الكهرباء من طاقة الرياح على مناطق السو احل سارت بسر عة، ونأتي المملكة المتحدة في الطليعة، إذ نم القضاء على بعض التحديات السياسية التي تو اجهها التوربينات البرية ونم السماح بالوصول إلى مورد الرياح الأقوى المتوفر على الثاطئ، وكما هو الحال 
مع الخلايا الفولطا الضوئية و الطاقة الشمسية، فإن تكلفة تكنولوجيا طاقة الرياح قد انخفضت بشكل ملحوظ في العقد الماضي، مما يجعل طاقة الرياح منافسة أو قريبة من درجة المنافسة من حيث التكلفة [5] .

\section{• طاقة الكتلة الحيوية:}

يشير مصطلح "الطاقة الحيوية" بشكل عام إلى استخدام المواد العضوية، النباتات أو مخلفات الحيو انات كمصدر للطاقة، ومع ذللك فإن الحقل يخضع لبلبلة وجل مستمرين، ويجب اتخاذ الحيطة لتمييز المصادر المختلفة والتقنيات المستخدمة لتوليد طاقة الكتلة الحيوية. ـ الكتلة الحيوية التقليدية: تمثل حوالي 10 \% من مجموع الطاقة المستهكة على كوكب الأرض، والكتلة الحيوية التقليدية هي حرق الخشب والمواد النباتية أو المخلفات الحيو انية من أجل تدفئة المنازل وطهي الطعام، إذا تم الحصول على الكتلة الحيوية من مصادر مستدامة، مثل غابة تدار بثكل جيد أو تفل من إنتاج قصب السكر، فإنه يمكن اعتبار ها شكلا من أشكال الطاقة المتجددة، ومع ذلك فإن معظم وقود الكتلة الحيوية التقليدية مصادره ليست مستدامة، وبالتالي يساهم في تدهور النظم الإيكولوجية المحلية، ويولد حرق الكتلة الحيوية التقليدية لأغر اض الطهي و التدفئة كميات كبيرة من تلوث الهو اء في الأماكن المغلقة، وله تأثثيرات صحية سلبية خطيرة، وخاصة

$$
\text { على النساء و الأطفال، الذين يقضون معظم وقتهم قرب المو اقد. }
$$

ـ الغاز الحيوي: ويتم إنتاج الغاز الحيوي عن طريق تخمير المواد القابلة للتحلل منل رَوْث الحيوانات أو النفايات النباتية، ومثل الغاز الطبيعي يمكن استخدام الغاز الحيوي لتدفئة المنازل وكوقود لمو اقد الطبخ، إن التكنولوجيا اللازمة لإنتاج الغاز الحيوي بسيطة وطويلة الأمد ورخيصة، ويمكن نشر ها بسهولة نسبية في المجتمعات الريفية الصغيرة لتحويل النفايات العضوية إلى مصدر وقود نظيف و وتجدد، ومع ذلك تجدر الإشارة إلى أن هذه التقنية تتطلب صيانة كبيرة ولم تسفر عن نتائج إيجابية في جميع البلدان، شريطة أن يتم تغذية الغاز الحيوي المنتج من نفايات المكبات في شبكة الغاز ، أو كما في الصين حيث يتم الترويج لهاضمي الغاز الحيوي لفو ائده للصحة العامة (إز الة النفايات) وبنفس القدر للحصول على الطاقة.

ـ الوقود الحيوي: يشير مصطلح الوقود الحيوي إلى عادة زرع المحاصيل فقط لاستخدامها في إنتاج الطاقة وعادة كوقود للنقل، فعلى سبيل المثال يمكن استخدام الذرة أو قصب السكر لصنع الإيثانول، في حين أن وقود الديزل الحيوي بمكن أن يصنع من الزيوت النباتية والدهون الحيو انية.

وللوقود الحيوي العديد من المز ايا، فخلافا لغير ها من مصادر الطاقة المتجدة يمكن أن تتنج المو اد العضوية الوقود الذي يمكن خلطه مع البنزين لتزويد وسائط النقل البري بالطاقة، ومع ذلك أثنارت زراعة المحاصيل لإنتاج الوقود الحيوي في السنوات الأخيرة جدلا كبير ا لأنها يمكن أن تحول الأر اضي الزراعية بعيدا عن إنتاج الغذاء مما يسهم في نقص المحاصيل وارتفاع أسعار المواد الغذائية وتفاقم الجوع في العالم، وتتساءل العديد من الدر اسات عما إذا كان الوقود الحيوي وخاصة من الذرة لإنتاج الإيثانول، هو أقل إثباعا بالكربون من 
الوقود الأحفوري، إذ أنه يساهم في تغيير استخدام الأراضي بشكل غير مباشر وفي التصحر وإز الة الغابات وزر اعة القطع والحرق، و التي تعتبر كلها مصادر كبيرة للغاز ات المسببة للاحتباس الحراري[6 ] ] ، وعلى الرغم من عديد القضايا الراهنة المتعلقة بإنتاج و استخدام الوقود الحيوي بدأت التطورات الحديثة بمعالجة بعض هذه التحديات لجيل الوقود الحيوي الأول، ويثير الجيل الثاني من الوقود الحيوي باستخدام المو اد السليولوزية وتطوير محاصيل وقود حيوي جديدة عداءا أقل بكثير مع صناعة الإنتاج الغذائي.

ـ الكهرباء من المخلفات الزراعية: خلافا لأنواع الوقود الحيوي التي غالبا ما تتنافس على الأراضي والموارد مع إنتاج الغذاء، يمكن أن تحرق مجموعة واسعة من منتجات النفايات الزراعية التي يتم التخلص منها عادة لتوليد الكهرباء، والبلد الرائد في هذا المجال هي موريشيوس، والتي وضعت إطار سياسة قوية لتشجيع المزارعين على استخدام التلف (النفايات العضوية من القصب الناجمة عن إنتاج السكر ) لتزويد مولدات بالطاقة التي تغذي الكهرباء في الثبكة الوطنية في البلاد. وفي المناطق خارج نطاق الثبكة، يمكن استخدام بعض النباتات التي كانت تعتبر في السابق أعثابا مثل الجاتروفا لإنتاج وقود بديل لتزويد مولدات الديزل بالطاقة، على الرغم من أنها عندما تزرع خصيصا لهذا الغرض يمكن أن تثير بعض نفس العيوب مثل الوقود الحيوي، ويمكن الاستفادة منها في الحصول على الكهرباء بعدة طرق منها [7]: • مرق المباشر أو غير المباشر. • عن طريق التخمر اللاهوائي. . • ( الأسمدة الكيماوية.

\section{ـ الطاقة الجوفية لحرارة باطن الأرض:}

إن ارتفاع درجة الحر ارة في باطن الأرض من الممكن الاستفادة منها في توليد طاقة يمكن استخدامها في توليد الكهرباء، وخاصة من استغلال درجات الحرارة المرتفعة للمياه الجوفية، وهناك ثلاثة استخدامات رئيسيه للحرارة الجوفية: • استخدام الحرارة بشكل مباشر من خلال خزانات تقع بالقرب من سطح الأرض. • إنشاء خز انات تحت سطح الأرض لعمق يتراوح ما بين ما 2-4 كم للحصول على مياه ساخنة تعمل على توليد الكهرباء. • تدفئة المباني عن طريق مضخات حر ارية تستفيد من حرارة الصخور أو المياه المتو اجدة بالقرب من سطح الأرض. وفي نهاية عام 2000 كانت القدرة الحرارية العظمى المركبة عالميا بالنسبة إلى تطبيقات التدفئة غير الكهربائية أعلى من 15000 ميغاو ات حر ارية بحسب تقرير وكالة الطاقة الحيوية الحرارية (IGA) عام 2015 [8 ]. 


\section{2- 2 - 2 الإطار النظري للتنمية المستدامة:}

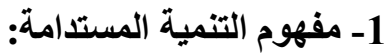

التنمية المستدامة هي نموذج شامل للأمم المتحدة، تم توصيف مفهوم التتمية المستدامة في تقرير للجنة ببورتلاند 1987 "هي التنمية التي تلبي احتياجات الحاضر دون المساس بقدرة الأجيال المقبلة على تلبية احتياجاتها الخاصة "، الاستدامة هي نموذج للتفكير حول المستقبل الاقتصادي الذي يضع في الحسبان الاعتبارات البيئية والاجتماعية والاقتصادية في إطار السعي للتنمية وتحسين جودة الحياة، ومن هنا أصبحت التتمية المستدامة مطلبا أساسيا لتحقيق العدالة والإنصاف في توزيع مكاسب التتمية والثروات بين الأجبال المختلفة.

\section{1}

قد برزت محاو لات عديدة لتعريف التتمية المستدامة منذ بداية ظهور ذلك الدفهوم سنة 1987، حيث اتفقت دول العالم في مؤتمر الأرض عام 1992 على تعريف التنمية المستدامة "أنها ضرورة إنجاز الحق في التنمية بحيث تتحقق على نحو متساو الحاجات التنموية والبيئية لأجيال الحاضر والمستقبل" وفيما يلي بعضا من هذه التعريفات:

\section{ـ تعريف اللجنة العالمية للبيئة والتنمية:}

التي شكلتها الأمم المتحدة لدراسة هذا الموضوع وقدمت هذا التعريف عام 1987 بعنو ان مستقلنا المشترك، إذا يعد هذا التعريف شاملا و مختصر اللتنمية المستدامة بتعريف "بأنها التنمية التي تلبي احتياجات الحاضر من دون المساومة بقرة الأجيال المقبلة على تلبية احتياجاتها" [9].

ـ - تعرف منظمة الأغذية والزراعة (الفاو) التنمية المستامة:

"بأنها إدارة وحماية قاعدة الموارد الطبيعية وتوجيه التغير التقني و المؤسسي بطريقة تضمن تحقيق استمر ار إرضاء الحاجات البشرية للأجبال الحالية و المستقبلية، إن تللك التتمية المستدامة (في الزر اعة والغابات و المصايد السمكية) تحمي الأرض و المياه والمصادر الور اثثة النباتية والحيو انية و لا تضر بالبيئة، وتتسم بأنها ملائمة من الناحية الفنية ومناسبة من الناحية الاقتصادية ومقبولة من الناحية

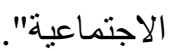

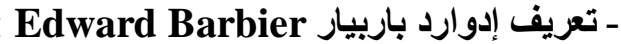

بأنها ذلك النشاط الاقتصادي الذي يودي إلى الارتفاع بالرفاهية الاجتماعية مع أكبر قدر من الحرص على الموارد الطبيعية المتاحة، وبأقل قدر من الأضرار والإساءة البيئية[10] ـ 


\section{2-1 - 2-1 أهداف التنمية المستدامة:}

تضع التنمية المستدامة في اعتبار ها مجموعة من الأهداف التي تسعى لتحقيقها، حيث تتمركز معظم أهداف التنمية المستدامة حول الحفاظ على البيئة وحسن استغلال الموارد الموجودة بها وإتاحة فرص للأجيال القادمة للاستفادة منها، وتتمنل أهداف التنمية المستدامة. 1. تحقيق حياة أفضل للبشر وذلك عن طريق الحفاظ على البيئة، والتعامل مع الطبيعية بما يحقق حياة أفضل للسكان. 2. تعزيز وعي البشر بالمشكلات البيئية القائمة وتنمية إحساسهم بالمسئولية تجاهها، وحثهم على المشاركة الفعّالة في إيجاد حلول مناسبة لها من خلال مشاركتهم في اقتر اح و إعداد وتنفيذ ومتابعة مشاريع التنمية المستدامة. 3. تحقيق الاستغلال الأمثل للموارد، حيث تواجه التنمية المستدامة مشكلة محدودية الموارد عن طريق الاستغلال الأمثل والكفء للموارد المتاحة، مما يتيح فرصة كبيرة للأجيال القادمة للاستفادة من الموارد المتاحة، مما يحقق درجة كبيرة من العدالة بين الأجيال الحالية و الأجيال القادمة.

4. تفعيل التكنولوجيا الحديثة وربطها بأهداف المجتمع، كما تعتمد التنمية المستدامة بشكل كبير على التكنولوجيا الحديثة، وتسعى دائما إلى تتمية استخدامها في تحقيق أهداف المجتمع، وذلك عن من خلال توعية المواطنين بأهمية التقنيات المختلفة في المجال التنموي، وكيفية استخدام المتاح و الجديد منها في تحسين نوعية حياة المجمع وتحقيق أهدافه المنشودة، دون أن يودي ذلك إلى مخاطر و أثار بيئية سالبة. بالإضافة إلى ذللى اعتمدت قمة الأمم المتحدة للتنمية المستدامة في 25 سبتمبر 2015 قرارا بعنوان "تحويل عالمنا: جدول أعمال 2030 للتنمية المستدامة" يشمل على 17 هدفا للتنمية المستدامة.

\section{3-1 - 2-1 مؤشرات التنمية المستدامة:}

في إطار السعي الجاد نحو تحقيق أهداف التنمية المستدامة، يستخدم الاقتصاديون بعض المؤشر ات التي تساهم في تقييم مدى تقدم الدول و المؤسسات لتحقيق أهداف التنمية المستدامة بصورة فعلية، حتى يستطيع صناع السياسة العامة استخدامها في عمليات صنع القرار، كما أن مؤشر التنمية المستدامة هو المؤشر الذي يحدد الطريق وما تحقق من أهداف، وكم هو البعد عن الهدف المنشود، والمؤشر الجيد هو الذي يحدد المشكلة قبل وقو عها.

وقبل الإشارة إلى تللك المؤشر ات لا بد من معرفة ما يجب أن يتو افر في تلك المؤشرات لنتمكن من الاعتماد عليها على أن تكون كالتالي: • ق قومية في المقام الأول من حيث المدى و الحجم. • ترتبط بالهدف الرئيسي لتقييم التقدم نحو التنمية المستدامة. 


$$
\text { • • • • • • مابلة للفهم، بمعنى أن تكون واضحة وبسيطة وغير غامضة إلى أقصى درجة ممكنة. }
$$

• تعتمد على البيانات المتاحة أو المتاحة بتكلفة معقولة، وموثقة وبجودة معلومة ويمكن تحديثها بانتظام.

\section{1}

اهتم الاقتصاديون في مرحلة مبكرة بالنمو الاقتصادي إن لم نقل بالتنمية، وضعو ا حول ذلك النظريات التي ركزت على عو امل الإنتاج وكماه، أو على جوانب النظر إليه عرضا وطلبا، أو على علاقات الإنتاج وبيئته، والتي تتمثل في:

\section{1}

حيث يصنف هذا المؤشر خصائص الجهاز الاقتصادي للبلد من خلال التعرّف على معدل متوسط الفرد من الكتلة الإجمالية للاخل، أو في شكل نسب مختلفة من الناتج القومي الإجمالي كمعدل التصدير أو الاستير اد أو الديون، إضافة إلى نسب القيم المضافة في الصناعات التحويلية والتي من شأنها أن تعزز كفاءة الإنتاج المحلية [11] ، والتي تساهم في رفع حصة الاستثمارات في الناتج الإجمالي، ونوسيع قاعدة الصادر ات من السلع و الخدمات.

\section{2 -تغيير أنماط الإنتاج والاستهلاك:}

و هي قضية رئيسية في التنمية المستدامة، حيث يتميز العالم بسيادة النزاعات الاستهلاكية في دول الثمال و أنماط الإنتاج غير المستدامة التي تستنزف الموارد الطبيعية سواء في دول الثمال أو دول الجنوب، فلا بد من تغيير هذه الأنماط بهدف المحافظة على تلك الموارد و إتاحتها لجميع سكان المعمورة بشكل متساو وضمان بقائها للأجيال المستقبلية، وكما تتحدد أيضا في نصيب الفرد من استهلاك الطاقة و إمكانية الحصول على هذه المصادر وضرورة تغيير منظومة الإمداد الطاقوي العالمي والانتقال من الوقود الأحفوري إلى الطاقات المتجددة، و الحد من إنتاج النفايات الصناعية الخطيرة [12] ـ

\section{3 -مؤشرات التنافسية:}

وضع المعهد العربي للتخطيط مؤشرات للتعبير عن هذه التنافسية في الدول النامية ومقارنتها مع عدد من الدول المتقدمة، وترتكز هذه الأخيرة على تحليل القيمة المضافة للصناعات التحويلية، وقياس مدخلات الزر اعة و إنتاجيتها ومقارنة نسب الصـادرات من السلع 
و الخدمات المنظورة و غير المنظورة نسبة للواردات، وقياس قيمة الدين مقابل الناتج الوطني الإجمالي، ومعدلات الانفتاح على التجارة الخارجية وشفافية المعاملات الدولية، إضافة إلى مجموع المساعدات الإنمائية الرسمية المقدة أو المتلقات.

\section{2]}

وتعني توفير الظروف للدول والبشر ليتمكنوا من تحقيق ما يلي:

1 ـالمساو اة الاجتماعية وتحقيق عدالة توزيع الثروة ومكافحة الفقر، و هناك مؤشرين لقياس مدى تحقيق الدول للعدالة الاجتماعية هما (نسبة عدد السكان تحت خط الفقر، ومقدار التفاوت بين الفئات الغنية والفئات الفقيرة).

2 ـالرعاية الصحية المناسبة لجميع فئات الشعب، وخاصة الاهتمام بالمناطق النائية والأرياف مع السيطرة على الأمراض المتوطنة و الأوبئة الناتجة عن تلوث البيئة والمقياس لمعرفة مدى تقدم الرعاية الصحية، حيث يتمثل في (معدلات وفيات الأمهات والأطفال و الر عاية الصحية الأولية، والعمر المتوقع عند الولادة، ونسبة التطعيم ضد الأمر اض المعدية). 3 ـالتعليم الذي يعدّ أهم حقوق الإنسان، لأنه هو السبيل الأهم لتحقيق التنمية المستدامة في أي مجتمع عصري، وذلك يحدث من خلال توجيه التعليم إلي أهمية التنمية وسبل تحقيقها ومجالاتها المختلفة، والعمل على زيادة التوعية عند الأفراد خاصة الفقيرة منهم وتعريفهم بأهمية التعليم على الفرد والمجتمع، ومن مؤشرات تقدم التعليم (نسبة الأمية، مدى استمرار الفرد في مسيرة التعليم، ونسبة إنفاق الدولة على التعليم و البحث العلمي). 4 ـالسكن و السكان حيث يؤثر النمو السكاني السريع، و هجرة سكان الريف للمدن على تحقيق التنمية المستدامة وتؤدي إلى إفشال خطط التنمية الاقتصادية و العمر انية للدولة، وتم إعداد مؤشرين لقياس ذلك هما (معدل النمو السكاني، ونصيب الفرد من الأبنية العمرانية). 5 ـالأمن الاجتماعي وحماية الأفراد من الجرائم ويتحقق ذلك من خلال تحقيق العدالة والديمقراطية والسلام الاجتماعي، ويقاس ذلك بمؤشر (عدد الجر ائم المرتكبة لكل 1000 فرد في المجتمع). 2 31 1 ـالإطار المؤسسي وهو يشمل إنشاء أطر مؤسسية مناسبة لتطبيق التنمية المستدامة من خلال وضع استراتيجيات وطنية لكل دولة، و التوقيع على اتفاقيات عالمية بشأن التنمية المستدامة. 2 ـقدرة مؤسسات الدولة على تحقيق التنمية المستدامة، وذلك من خلال الإمكانيات البشرية و العلمية والاقتصادية والسياسية. 


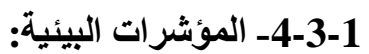

وتتمثل في قضايا البيئة المعاصرة.

1. التغير في الغلاف الغازي للأرض ويتمثل في (الاحتباس الحراري، وثقب الأوزون)، وتغير المناخ ويقاس من خلال (تحديد انبعاثات غاز ثاني أكسيد الكربون في الجو) ومعالجة التلوث الهو ائي الزائد، وتحسين نوعية الهو اء من خلال بروتوكولات (كيتو، ومونتريال). 2. استخدامات الأرض من خلال حمايتها من التدهور البيئي، ووقف إزالة الغابات الطبيعية، والزحف العمراني على الأراضي الزراعية مع العمل على تحقيق تتمية مستدامة للإنتاج الزر اعي و الغابي و الرعوي. 3. المسطحات المائية وحمايتها من التلوث وذلك بوقق الصيد البحري الجائر، ومعرفة منسوب التلوث في المياه، وحساب كمية المياه بكل أنواعها ومقدار ما تفقده كل سنة، وتتمية الثروة السمكية وحماية أنواع الأسماك المعرضة للانقر اض، وحل مشكلة ارتفاع منسوب سطح البحر في السنوات القادمة والذي يشكل تهايد كبير سيؤدى إلى إغراق مساحات شاسعة من الجزر واليابس.

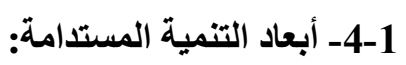

وفقا للتعريف التتمية المستدامة يتضح جليا أنها تتضمن أربعة أبعاد تتسم بالترابط والتكامل في إطار يتميز بالتنظيم والاستغلال العقلاني للموارد.

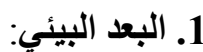

تهدف التتمية المستدامة إلى تحقيق العديد من الأهداف البيئية: كالاستخدام الرشيد للموارد الناضبة، بمعنى حفظ الأصول الطبيعية بحيث يترك للأجيال القادمة بيئة مماثلة، حيث إنه لا توجد بدائل لتلك الموارد، ومر اعاة القدرة المحدودة للبيئة على استبعاب النفايات، والتحديد الدقيق للكمية التي ينبغي استخدامها من كل مورد من الموارد الناضبة، وبالنالي فإن الهدف الأمثل للتنمية المستدامة هي التوفيق بين التتمية الاقتصادية والمحافظة على البيئة مع مر اعاة حقوق الأجيال القادمة في المو ارد الطبيعية، خاصة الناضبة منها.

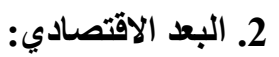
يهدف هذا البعد بالنسبة للبلدان الغنية إلى إجر اء تخفيضات متو اصلة في مستويات استهلاك الطاقة و الموارد الطبيعية، والتي تصل إلى أضعاف أضعافها في الدول الغنية مقارنة بالدول الفقيرة، فمثلا يصل استهلاك الطاقة الناجمة عن النفط والغاز والفحم في الولايات المتحدة إلى مستوى أعلى منه في الهند بـ 33 مرة. 


\section{3. البعد الاجتماعي:}

تشمل عملية التنمية المستدامة تتمية بشرية من خلال العمل على تحسين مستوى الرعاية الصحية والتعليم، فضلا عن عنصر المشاركة حيث ينبخي أن يشارك الناس في صنع القرارات التنموية التي تؤثر في حياتهم، ويشكل الإنسان محور عملية التنمية المستدامة و التعريفات المقدمة حولها حيث تشير إلى عنصر العدالة والإنصاف والمساو اة، من خلال إنصاف الأجيال المقبلة والتي يجب أخذ مصالحها في الاعتبار، كما يجب إنصاف القسم من البشر الحي حاليا الذين لا يتمتعون بفرص منساوية مع غير هم، في الحصول على الموارد الطبيعية و الخدمات الاجنماعية، و التنمية المستدامة تهذف إلى القضاء على ذلك التفاوت الصار خ بين هذه الفئات من خلال تقديم القروض للقطاعات الاقتصادية، وتحسين فرص التعليم والر عاية الصحية.

4. - 2 البعد التكنولوجي:

و هي تحقيق تحول سريع في القاعدة التكنولوجية للمجتمعات الصناعية إلى تكنولوجيا جديدة أنظف و أكفأ و أقدر على الحد من تلوث البيئة، وإيجاد تحول تكنولوجي في البلدان النامية الآخذة في التصنيع، مع تفادي تكرار أخطاء التنمية وتفادي التلوث البيئي الذي تسببت فيه الدول الصناعية بحيث يتم التوفيق بين أهداف التنمية والقو اعد التي تفرضها البيئة. المبحث الثاني: واقع الطاقات المتجددة في الجزائر 1 -نبذة عن الطاقات المتجددة 2012:

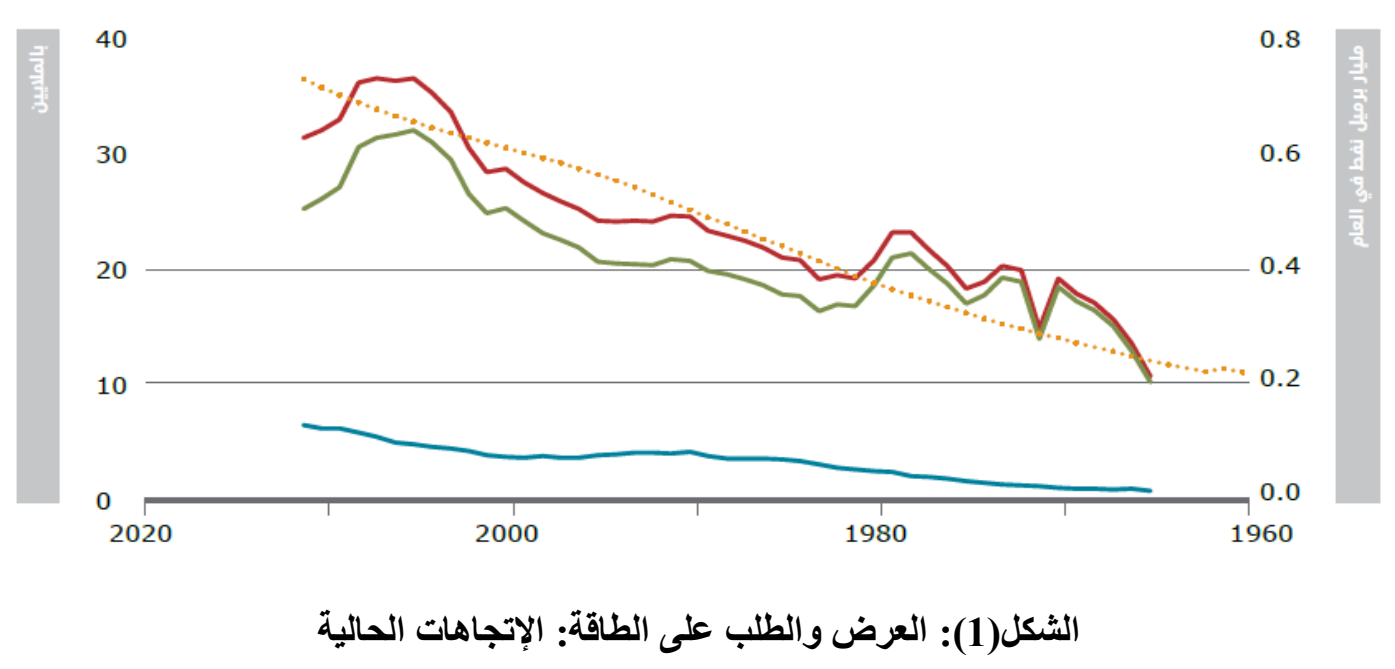

المصدر: الوكالة الدولية للطاقة، 2011، وبريتيش بتروليوم 2012. 


\section{أهداف الطاقة المتجددة 2030}

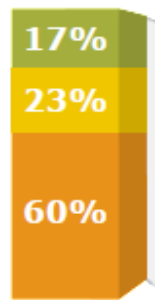

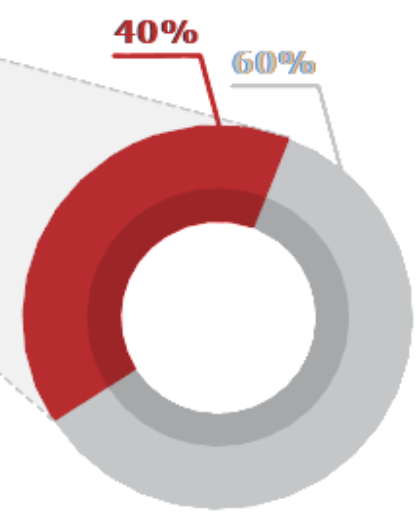

\section{القدرات المركبة حالياً}

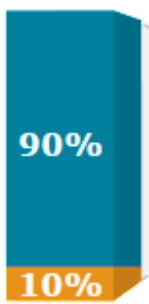

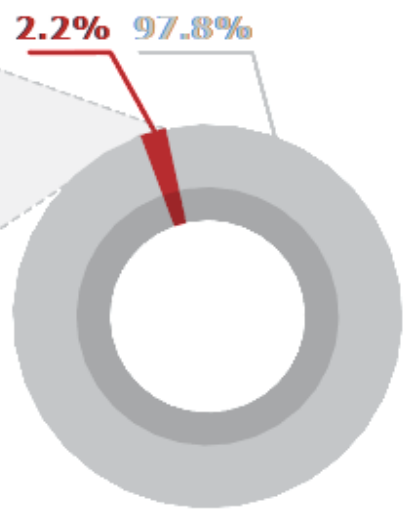

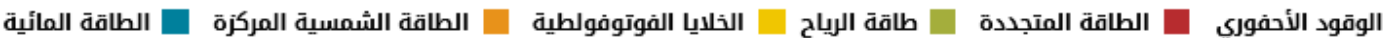

\begin{tabular}{|c|c|c|c|c|c|c|c|c|c|c|c|c|}
\hline المستهدف & الإجِمالي & الشماقة المركزة & الفوتوفولطية الخلايا & طاقة & & الإحمالي & 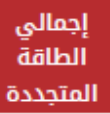 & $\begin{array}{l}\text { المائية } \\
\text { الماقية }\end{array}$ & 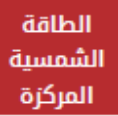 & الفوتوفولطية الخلايا & طاقة الرياح & \\
\hline 2013 & 41 & 25 & 6 & 10 & ميجاواط & 11390 & 253 & 228 & 25 & 0 & 0 & ميجاواط \\
\hline 2015 & 557 & 325 & 182 & 50 & ميجِاواط & & & & & & & \\
\hline 2020 & 2601 & 1500 & 831 & 270 & ميجاواط & & & & & & & \\
\hline 2030 & 12000 & 7200 & 2800 & 2000 & ميجاواط & & & & & & & \\
\hline
\end{tabular}

\section{الثل(2): القدرات المركبة حاليا وأهداف الطاقة المتجدة 2030}

\section{المصدر: المركز الإقليمي للطاقة المتجدة وكفاعة الطاقة، نبذة عن الطاقة المتجددة في الجزائر، 2013، ص1.}

يوضح الثكل2، سعي الجزائر من خلال مشاريعها الاستثمارية في مجال الطاقات المتجددة إلى بلوغ قيمة معتبرة من إنتاج الطاقة ذات المصادر المتجددة، تقدر بنسبة 40\% من الإنتاج الوطني الكلي للطاقة، بعدما كانت تمثل نسبة 2.2 \% سنة 2012 ، وتركز في برنامجها على الطاقة الثمسية حيث تتوقع أن تكون نسبة الطاقة المتولدة من أصل شمسي 83\% ، وتمثل 60\% منها بتقنية الطاقة الثمسية المركزة، و 23\% باستخدام الخلايا الفوتوضوئية، و هذا ما يعكس القدرات المتر اكمة المعتبرة للطاقة الثمسية، أما نسبة 17\% فهي موجهة للطاقة الرياح، ولكن تبقى الطاقة الأحفورية تمثل أكبر حصة من الطاقة الوطنية بنسبة\% \% في أفق 2030 إلا أنه يوجد تحسن كبير مقارنة بالقدر ات المركبة لسنة 2012 التي كانت تمثل نسبة 98\% من إجمالي الطاقة الوطنية.

إن من أهم مصادر الطاقة المتجددة المتوفرة في الجزائر حاليا، وتلك المتوقع أن يكون لها شأن في توفير الطاقة في المستقبل، هي كل من الطاقة الثمسية بالدرجة الأولى وطاقة الرياح و الطاقة المائية. 
نظر الموقعها الجغر افي تملك الجزائر واحدا من أهم القدرات الثمسية في العالم، حيث إن مدة إثراق الثمس على كامل التراب الوطني تتعدى 2000 ساعة سنويا وتصل إلى 3900 ساعة سنويا في الهضاب العليا والصحر اء، إن الطاقة المحصل عليها يوميا على مساحة أفقية تقدر ب 1م² هي 5 كيلوو اطساعي على معظم أجزاء التزراب الوطني أي حوالي 1700 كيلوو اط ساعي/م/السنة في الثمال و2263 كيلوو اط ساعي/م/السنة في الجنوب، و الجدول المو الي يوضح القدرات الشمسية في الجزائر: الجدول(1): القدرات الشمسية في الجزائر

\begin{tabular}{|c|c|c|c|}
\hline الصحراء & الهضاب العليا & المنطقة الساحلية & المناطق \\
\hline 86 & 10 & 4 & مساحة\%\% \\
\hline 3500 & 3000 & 2650 & معدل مدة إنشر اقة الشمس \\
\hline 2650 & 1900 & 1700 & معدل الطاقة المحصل عليهاعـ/السنة) \\
\hline
\end{tabular}

المصدر: وزارة الطاقة والمناجم، دليل الطاقات المتجددة، 2007، ص39.

من بين أهم مقومات الطاقة الثمسية بالجز ائر ما يلي[14]: • وفرة الأر اضي الصحر اوية المشمسة أغلب أيام السنة كما أن الشمس تمتذ بـــ أكثر من 2000 ساعة في السنة. • تعد صحر اء الجزائر من أكبر الصحاري في العالم وتمتاز بالحرارة الثديدة خاصة في فصل الصيف حيث تفوق درجة الحرارة 60 درجة، وهي تمثل مساحة الصحر اء في الجزائر أكثر من 80 \% ، مما يساعدها من استغلال أكثر للطاقة الثمسية. • تشير الكثير من الدر اسات إلى أن الطاقة الثمسية التي تمتلكها الجزائر تتيح لها حتى فرصة تصدير هذا النوع من الطاقة لدول الأخرى، وذلك لاتساع مساحة الجز ائر واستمر ار تعرضها لكميات عالية من موجات الإشعاع الضوئي والكهرومغناطيسي الصادر من الثمس. • إن هناك التزامات للعديد من دول العالم ومن ضمنها الجزائر في مؤشر المناخ الدولي في كونها تعمل على تخفيض الإنبعاثات الملوثة التي تسبب الاحتباس الحراري وتغير المناخ.

• توجد بالجزائر مجمعات قروية صغيرة متفرقة ومتباعدة ، حيث يقدر عدد سكان الريف 41 \% من إجمالي السكان وأنه قد يتعذر لأسباب عملية أو اقتصادية ربط هذه القرى و الأرياف في بعض الأحيان بالثبكة الرئيسية للكهرباء لذا فإن الحل المنطقي في هذه الحالة هو استغلال الطاقة الشمسية في هذه المجمعات النائية. • كثرة الطرق التي يمكن بها استغلال الطاقة الثمسية بفعالية في الجز ائر ويمن تصنيفها في ثلاث فئات رئيسية هي، التطبيقات الحر ارية و إنتاج الكهرباء و العمليات الكيميائية. 
• انخفاض الغيوم في كثير من المناطق الصحر اوية المؤهلة لهذا النوع من الاستغلال الطاقوي. • • لا تعاني الجز ائر من مشكل المساحة المطلوبة لتشيد الألواح الثمسية ومستلزماتها وللحصول على 1000 واط من الكهرباء نحتاج إلى مساحة من 7 إلى 10 منر مربع من هذه الألواح.

• أثتتت العديد من در اسات الجدوى في عدة دول من بينها الجزائر ، أنه يمكن استعادة رأس المال المستثمر في الطاقة الثمسية خلال فترة تتر اوح بين ثلاث وخمس سنو ات تتمكن بعدها الجهة المنفذة لمشاريع الطاقة الشمسية من الحصول على طاقة نظيفة منخفضة التكلفة. 2-2-2 - طاقة الرياح: - 2

يتغير المورد الريعي في الجزائر من مكان إلى آخر وهذا ناتج أساسا عن الطبوغر افيا وعن مناخ جد متتوع، حيث تنقسم الجزائر إلى منطقتين جغر افيتين كبيرتين ومتميزتين، الثمال الذي يحده البحر الأبيض المتوسط وبتضاريس جبلية تمثلها سلسلتي الأطلس التلي و الصحر اوي، بين هاتين السلسلتين توجد السهول و الهضاب العليا ذات المناخ القاري، وتتميز الجزائر بمناطق غنية بسرعة رياح جيدة و اقتصادية تبلغ أكثر من 5م/ثا، كمنطقة تيارت، وهران، تتدوف، كما نلاحظ أن أكثر المناطق سر عة للرياح كمنطقة عين صالح، تيميمون، وأدرار بحيث تبلغ سرعة الرياح 6م/ثا، مما يجعل هذه الحقول مناسبة لإقامة مز ارع هو ائية لإنتاج الطاقة الكهربائية[15] ـ

\section{2-2-2 طاقة حرارة الأرض الجوفية:}

يشكل كلا الجور اسي في الثمال الجزائري احتياطيا هاما لحر ارة الأرض الجوفية ويؤدي إلى وجود أكثر من 20 منبع مياه معدنية حارة و اقعة أساسا في مناطق شمال شرق وشمال غرب البلاد، نوجد هذه المنابع في درجات حرارية غالبا ما تزيد عن 40 درجة مئوية، و المنبع الأكثر حر ارة هو منبع حمام مسخوطين 69 درجة مئوية، إن هذه الطفرات الطبيعية التي هي على العموم تسربات لخز انات موجودة تفوق لوحدها أكثر من 2م3 /ثا من الماء الحار ، و هذا لا يمثل إلا جز عا صغير امن إنتاج الخزانات أكثر ها نحو الجنوب، يشكل تكوين القاري الكبيس خزانا واسعا من حرارة الأرض الجوفية، يمتد على آلاف كم²، ويتم استغلال هذا الخزان المسمى عامة بـ طبقة ألبية من خلال تنقبب بأكثر من 4م³ثا، لو جمعنا التدفق الناتج عن هذه الطبقة الألبية والتدفق الكلي لمنابع المياه المعدنية الحارة، فهذا يمثل على مستوى الاسنطاعة أكثر من 700 ميغاو اط [16]. 42 يمكن الاعتماد على النفايات المنزلية، بشكل أساسي في توليد الغاز الحيوي من خلال حرق النفايات، وقدرت كتلة النفايات المنزلية في سنة 2013 بحو الي 10.3 مليون طن، مما يسمح بإنتاج حوالي 716.8 مليون م³ من الغاز الحيوي، كما يمكن الاستفادة من المواد العضوية المترسبة في محطات معالجة مياه الصرف الصحي في إنتاج الغاز الحيوي المستخدم لإنتاج الحرارة والكهرباء[17] ـ 


\section{المبحث الثالث: الاستثمار في البرنامج الوطني للطاقات المتجددة:}

إن تتمية الطاقات المتجدة في الجز ائر تحظى باهتمام خاص من طرف السلطات العمومية التي تسعى لإعطاء دفعة جديدة لهذا القطاع كبديل للطاقات الأحفورية متناقصة الموارد، وهذا عبر إطلاق برنامج طموح لتطوير الطاقات المتجددة في فيفري 2011، وتم مر اجعته في ماي 2015، ولتجسيد البرنامج يتعين على الدولة استثمار حوالي 120 مليار دو لار، وتهدف الجزائر من خلال هذا البرنامج الطموح إلى إنتاج 40 \%من مصادر طاقات متجددة في آفاق 2030، أما بالنسبة لبرنامج إنتاج الكهرباء المتجددة والموجهة إلى السوق الوطني المقدرة بـ 12000MW سوف يتم تطويره عبر المر احل التالية [18]:

1 -برنامج إنتاج الكهرباء المتجددة: المرحلة الأولى 2013-2011: تتضمن إنشاء المشاريع النموذجية (PROJETS PILOTES) لاختبار مدى نجاعة مختلف التكنولوجيات المستخدمة في مجال الطاقات المتجددة. المرحلة الثانية: 2014-2015: البدء في تنفيذ البرنامج.

المرحلة الثالثة: 2016-2020: تنفيذ البرنامج على نطاق واسع، حيث الجدول الموالي يوضح كمية الطاقة المتجددة المر اد إنتاجها حسب كل مصدر من مصادر الطاقة المتجددة. الجدول(2): البرنامج الوطني التطوير الطاقات المتجددة

\begin{tabular}{|c|c|c|c|}
\hline الإجمالي & المرحلة الثانية & المرحلة الأولى & الوحدة: ميغاواط \\
\hline 13575 & 10575 & 3000 & الفوتو ضوئية \\
\hline 5010 & 4000 & 1010 & الرياح \\
\hline 2000 & 2000 & - & الطاقة الشمسية المركزة \\
\hline 400 & 250 & 150 & انتاج طاقة مزدوجة \\
\hline 1000 & 640 & 360 & الكتلة الحيوية \\
\hline 15 & 10 & 05 & حرارة الأرض الجوفية \\
\hline 22000 & 17475 & 4525 & الإجمالي \\
\hline
\end{tabular}

المصدر: وزارة الطاقة والمناجم، البرنامج الوطني لتطوير الطاقات الجديدة والمتجدةة.

2019/11/03http://www.energy.gov.dz

يتضح من الجدول أعلاه أن الاعتماد الأكبر سوف يكون على الطاقة الثمسية في إنتاج الطاقة النظيفة، ثم تليها طاقة الرياح وهذا لكون القدرات الثمسية التي تتوفر عليها الجز ائر تعد كبيرة جدا، كما تتطلع الجزائر إلى تصدير 10.000 ميغاو اط من 22.000 ميغاواط، تم برمجتها خلال العقدين المقبلين، في حين توجه 12.000 ميغاو اط لتلبية الطلب الوطني على الكهرباء[19] ـ 
تخطط شركة الكهرباء والطاقات المتجدة لإنتاج حوالي 295 ميغاواط من الكهرباء عن طريق الطاقات البديلة في عدة ولايات بالهضاب العليا خلال الصائفة المقبلة، في إطار برنامج يستهدف إنجاز 23 محطة لتوليد 350 ميغاو اط من الكهرباء عبر الوطن. ـانطلق برنامج تعميم الطاقات المتجدة منذ 2011، وشركة الكهرباء و الطاقات المتجددة حديثة النشأة تعتبر شريكا فعالا في هذا البرنامج منذ 2013 في إطار الحركية التي يشهدها مجمع سونلغاز، حيث تم تكليف الثركة بإنجاز هذا المشروع الذي يستهذف إنجاز 21 محطة تنتج 350 ميغاو اط، ودخلت 10 وحدات منها في الخدمة، أما باقي الوحدات فتوجد في طور الإنجاز بوتيرة سريعة، وقد تم استلامها خلال صائفة 2016، تضاف إلى محطتين تجريبيتين نم إنجاز هما قبل انطلاق المشروع، واحدة بغرداية مجزة بأحدث تكنولوجيات الصفائح الثمسية والثانية في و لاية أدرار التي ينت فيها توليد الكهرباء عن طريق الطاقة عبر الرياح بمنطقة كابرتان بسعة 10 ميغاو اط، شرعتا في الخدمة منذ صائفة 2014 ليصبح عدد محطات توليد الكهرباء عن طريق الطاقات المتجددة 23 محطة على المستوى الوطني، لاسيما في الجنوب الكبير و الهضاب، و عديد المحطات دخلت في الخدمة على غرار محطة جانت و7 محطات بأدرار وتمنراست و عين صالح، بينما بلغت نسبة التغطية في أدرار حو الي 60 بالمائة، تليها تمنر است بحوالي 30 بالمائة وجانت بـ 3 ميغاو اطوتندوف 40 بالمائة

$$
\text { بـ } 9 \text { ميغاو اط [20] }
$$

- يهدف البرنامج الوطني لتطوير الطاقات المتجددة إلى إحلال الطاقات التقليدية بطاقة المركزات الثمسية دفعت هذه الاستر اتيجية إلى العمل على إقامة البنى التحتية اللازمة لتطوير معدات و إنشاء محطات توليد من أجل إحلال الطلب المحلي بالطاقة الثمسية والتصدير في الطاقة الشمسية باستعمال لاقطات المستقبل، حيث تم إنشاء أول محطة هجينة تعمل بالغاز الطبيعي والطاقة الشمسية استلمت في جوان 1011 وبتكلفة قدرت بـ 315 مليون يورو، وبمدة إنجازه نراوحت بـ 33 شهر في إطار الثر اكة مع مجمع ABENER الإسباني بحاسي رمل، حيث تساهم الطاقة الثمسية في إنتاج 23 ميغاوات من أصل إجمالي يقدر بـ 4234 جيغاوات، وتقوم المحطة بييع الكهرباء المولد من المصادر الهجينة لمركب سوناطر اك الجزائري من أجل تغطية حاجيات الجنوب من الكهرباء . ـقد وضعت السياسات الوطنية لتطوير الطاقات المتجددة ضمن إطار قانوني ونصوص تنظيمية، حيث تمثلت النصوص الرئيسية في قانون التحكم في الطاقة وقانون ترقية الطاقات المتجددة في إطار التنمية المستدامة إلى جانب قانون الكهرباء والتوزيع العمومي للغاز ، وترنكز هذه السياسات على مجموعة من الهيئات والمؤسسات الاقتصادية، بحيث نهنم كل واحدة منها، في حدود اختصاصها، بتطوير الطاقات المتجددة، وهنالك ثلاث هيئات تابعة لقطاع التعليم العالي والبحث العلمي تنشط منذ سنة 1988 في هذا المجال نذكر منها [21] : CDER UDES UDTS - 
أما بداخل قطاع الطاقة فيتم التكفل بالنشاط المتعلق بترقية الطاقات المتجددة من طرف وزارة الطاقة والمناجم، ووكالة ترقية و عقلنة استعمال الطاقة UPRUE ومن جهة أخرى يتدخل مركز البحث وتطوير الكهرباء والغاز CREDEG في إنجاز وصيانة التجهيزات الثمسية التي تم إنتاجها في إطار البرنامج الوطني للإنارة الريفية، أما في قطاع الفلاحة فتجدر الإشارة إلى وجود المحافظة السامية لتنمية السهوب HCDS تقوم بإنجاز برامج هامة في ميدا ضخ المياه والتزويد بالكهرباء عن طريق الطاقة الشمسية لفائدة المناطق السهبية، أما على مستوى المتعاملين الاقتصاديين، فهناك عدة شركات تنشط في ميدان الطاقات المتجدة بغرض وضع إطار تثمن فيه كل جهود البحث، ومن أجل إعداد أداة فعالة تسمح بوضع سياسة وطنية حول الطاقات المتجدةة، قامت وزارة الطاقة والمناجم بإنشاء شركة مشتركة بين كل من سوناطر اك، سونلغاز ومجموعة سيم، ويتعلق الأمر بمشروع NEAL نيو اينارجي ألجيريا المؤسسة سنة 2002 وتتمنل مهمتها في نطوير الطاقات المتجدة في الجزائر على المستوى الصناعي. 2 -برنامج الطاقات المتجددة في الجزائر (2015-2030):

إن إدماج الطاقة المتجددة في مزيج الطاقة الوطنية يمثل تحديا كبير امن أجل الحفاظ على الموارد الأحفورية، وتنويع فروع إنتاج الكهرباء و المساهمة في التنمية المستدامة، بفضل البرنامج الوطني للطاقات المتجددة 2011-2030 ، تتموقع هذه الطاقات في صميم السياسات الطاقوية و الاقتصادية المتبعة من طرف الجز ائر، لاسيما من خلال تطوير الطاقة الثمسية وطاقة الرياح على نطاق واسع، و إخخال فروع الكتلة الحيوية (تثمين استعادة النفايات)، الطاقة الحر ارية والأرضية، وتطوير الطاقة الثمسية الحرارية. -إن سعة برنامج الطاقة المتجددة المطلوب إنجازه لتلبية احتياجات السوق الوطنية خلال الفترة 2015-2030 يقدر ب 22000 ميغاو اط، حيث سينم تحقيق 4500 ميغاو اط منه بحلول عام 2020. يتوزع هذا البرنامج حسب القطاعات التكنولوجية كما يلي [22] : ـ الطاقة الثمسية: 13575 ميغاو اط. ـ طاقة الرياح: 5010 ميغاو اط. ـ الطاقة الحرارية: 2000 200 ميغاو اط ـ الكتلة الحيوية: 1000 ميغاو اط. ـ التوليد المشترك للطاقة: 400 ميغاو اط. ـ الطاقة الحرارية الأرضية: 15 ميغاو اط - سيسمح تحقيق هذا البرنامج بالوصول في آفاق 2030 لحصة من الطاقات المتجددة بنسبة 27٪ من الحصيلة الوطنية لإنتاج الكهرباء. 
- إن إنتاج 22000 ميغاو اط من الطاقات المتجددة سيسمح بادخار 300 مليار متر مكعب من حجم الغاز الطبيعي، أي ما يعادل 8 مرات الاستهلاك الوطني لسنة 2014، وفقا للأنظمة المعدول بها، فإن إنجاز هذا البرنامج مفتوح أمام المستثمرين من القطاع العام والخاص وطنيين وأجانب.

- إن تنفيذ هذا البرنامج يحصل على مساهمة معتبرة ومتعددة الأوجه للدولة و التي تتدخل سيما من خلال الصندوق الوطني للطاقات المتجددة والإنتاج المزدو ج وتدعيما لهذا البرنامج أنشأت الحكومة الجزائرية "المعهد الجز ائري للبحث و التطوير للطاقات المتجددة" وكذا شبكة مر اكز للبحث والتطوير، مثل مركز البحث و التطوير للكهرباء والغاز، الوكالة الوطنية لترقية وترشيد استعمال الطاقة، مركز تطوير الطاقات المتجددة ووحدة تطوير معدات الطاقة الثمسية. 3 -مخطط تطوير الاستثمارات في الطاقات المتجددة: سيتم تثبيت قدر ات الطاقة المتجددة وفقا لخصوصيات كل منطقة: ـ منطقة الجنوب: لتهجين المر اكز الموجودة، وتغذية المواقع المتفرقة حسب توفر المساحات وأهمية القدرات من الطاقة الشمسية وطاقة الرياح. ـ منطقة الهضاب العليا: حسب قدر اتها من أشعة الثمس و الرياح مع إمكانية اقتناء قطع الأر اضي. ـ المناطق الساحلية: حسب إمكانية توفر الأوعية العقارية مع استغلال كل الفضاءات مثل الأسطح و الثرفات والبنايات و المساحات الأخرى غير المستعملة. وقد تم وضع برنامج وطني للبحوث في هذا المجال لمر افقة استر اتيجية تطوير الطاقات المتجدةة، حيث تصبو الأهداف العلمية لهذا البرنامج إلى تقييم ودائع الطاقة المتجددة، التحكم في عملية تحويل وتخزين هذه الطاقات وتطوير المهارات اللازمة، بدءا من الدراسة حتى الانتهاء من الإنجاز في موقع النتبيت. 4 -محطات الطاقات المتجدةة في الجزائر: 1- عدد المحطات المنجزة (جوان 2017): 24 محطة (23 فولطاضوئية و 01 رياحية). 2- الطاقة الإجمالية: 352.3 ميغاو اط ( 342.1 ميغاو اط فولطا ضوئية و 10.2 ميغاو اطرياحية). 3- الطاقة المنتجة (جوان 2017): 470.318 جيغاو اط ساعي (418.318 جيغاو اط ساعي فولطا ضوئية و 51.579 جيغاو اط ساعي رياحية).

$$
\text { 5- 5ـ العراقيل التي تعيق الاستثمار في الطاقات المتجددة في الجزائر: }
$$

هنالك جملة من العر اقيل و القيود التي تمثل عقبات أمام الاستثمار في قطاع الطاقات الجديدة والمتجددة في الجزائر نذكر منها[23]: 


\section{1-5 التكاليف العالية:}

إن إمكانيات وموارد استغلال الطاقة المتجددة متوفرة في الجزائر خاصة منها الطاقة الثمسية والربحية، إلا أن المشكلة تكمن في ارتفاع التكاليف التي تحد من توسع تلك الصناعة من جوانب عديدة، وجانب التكاليف في مجال الصناعات الاستثمارية مرتبط بمدى التكنولوجية المتاحة في كيفية تدوير و الاستغلال الأمثل للموارد الكامنة في الطاقة المتجدة، حيث تعتبر أسعار الاستثمار عاملا حاسما لتقييم الجدوى الاقتصادية لمشاريع الطاقة وفق افتراضات معينة، ومنه يعتبر عامل التكاليف من أهم العو امل المؤثرة في مستوى الجدوى الاقتصادية لمشاريع الطاقة المتجددة في الجزائر، كونها مرتبطة بآثار التقدم التكنولوجي و الذي يختلف من مصدر لآخر.

\section{2-5 أسعار النفط:}

تعتبر أسعار النفط عاملا رئيسيا مؤثرا في الجدوى الاقتصادية لمشاريع الطاقة المتجددة في الجزائر ومحددا لمستقلها القريب، وبالأخص بالنسبة للمشاريع ذات الطبيعة المتكاملة أي التي تشمل على مر احل التشغيل الأولى (وذلك على ضوء تكاليفها العالية ومبالغ الاستثمارات الضخمة التي تستلزمها تلك المشاريع)، ويعزى ذلك إلى أن منتجات مشاريع الطاقة المتجددة في الجز ائر قد تكون مكملة في بعض الأحيان لمنتجات الطاقة التقليدية، وبالنالي يتأثر الطلب عليها بأسعار تلكك المنتجات، ولا شك بأن تصاعد أسعار النفط والغاز الطبيعي خلال الأعوام القليلة الأخيرة قد ساهم وإلى حد كبير في تحسين الجدوى الاقتصادية لمشاريع الطاقة المتجددة في العالم ككل، وز اد من جاذيبة الاستثمار في تلك الصناعة، و هذه العلاقة ما بين تطوير الطاقة المتجدة واستغلالها في مجالات عديدة للطاقة هي معاكسة للانطباع الذي مفاده أن التوسع في إنتاج الطاقة المتجددة يمثل تهديدا حقققيا لصناعة النفط التقليدية، وما يؤدي إليه ذلك من انخفاض في أسعار ها على الأمد البعيد مما يضر بعائدات الجز ائر و الدول النفطية من الطاقة.

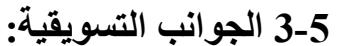

تعاني معظم مشاريع الطاقة المتجدة من مشاكل مختلفة من الناحية التسويقية مما قد يحد من التوسع في إنتاجها من جهة، والتقليل من درجة منافستها مع المنتجات التقليدية المشابهة من جهة أخرى، فمثلا يعاني بعض أنو اع الطاقة المتجددة من صعوبات في عمليات التصدير إلى الأسو اق الأخرى (النقل و الإيصال) كما يعاني البعض الأخر من مشاكل الانقطاع، كون الطاقة المتجدة منقطعة وغير مستمرة (intermittent)، وبالنالي فهي تحتاج إلى تخزين، ما يجعلها مكلفة وهي أيضا منتشرة ومبعثرة. 
تحتم عملية الانتقال الطاقوي السلس على الدولة الجزائرية التفكير بشكل جدي في إيجاد الآليات والميكانزمات الناجعة لإرساء دعائم قوية يقوم عليها قطاع الطاقات المتجددة، فالوضعية الاقتصادية الصعبة التي تمر بها البلاد حاليا تعد فرصة حقيقية لتركيز الجهود على هذا القطاع، من خلال تفعيل الاستثمار الوطني العمومي و الخاص، وكذا الاستعانة بالخبرات الأجنبية بخلق مشاريع مشتركة اعتمادا على الاستثمار الأجنبي المباشر، باعتبار أن هذا القطاع يعتمد على تكنولوجيات جد متقدمة تساهم في تقليل تكاليف الاستثمار التي تعد مرتفعة نسبيا في الوقت الر اهن، فإيجاد مناخ استثماري محفز يعد الخطوة الأولى من خلال سن قو انين وتشريعات مشجعة على الاستثمار وخاصة الاستثمار الأجنبي، والجز ائر بإمكاناتها الطبيعية والبشرية قادرة على أن تحقق قفزة اقتصادية نوعية وفي فترة زمنية قياسية إذا ما تو افرت الإر ادة السياسية الحقيقية وتضافرت كل الجهود الر امية لتحقيق هذا الهدف.

ـ أصبحت الطاقة المتجددة مصدر رئيسي للطاقة وهو تطور يتماثى مع دخولنا عقد الطاقة للجميع.

ـ تقوم الطاقة المتجددة بدور هام في نرجمة أبعاد التنمية المستدامة، حيث تساهم مشاريعها التنموية في تحقيق المكاسب الاقتصادية، وتحسين الأوضاع الاجتماعية والحفاظ على الموروث البيئي للأجيال القادمة، بهدف تحقيق التنمية المستدامة. ـ للطاقة المتجدة القدرة على تلبية حاجة التطور في الجزائر، فضلا عن قدرتها على زيادة النطور والنمو على نطاق واسع. ـ الحد من الآثار الصحية والبيئية المرتبطة باستخدام الوقود الأحفوري و الوقود النووي، وتحسين فرص التعليم، وإيجاد فرص عمل، و الحد من الفقر ، والمساو اة بين الجنسين. - تساهم الطاقة المتجددة في جهود حماية المناخ.

ـ تلعب الحكومة دور بالغ الأهمية في دعم قطاع الطاقة المتجددة وذلك من خلال وضع سياسات مناسبة وأطر تنظيمية وآليات تحفيزية لتطوير ونشر حلول الطاقة المتجددة. 
ـالقيام بمشاريع رائدة وكبيرة في مجال الطاقة المتجددة وتدريب الكو ادر البشرية. تطوير التقنيات الحديثة في مجال الطاقة المتجددة وتنشيط حركة البحث خاصة في مجال مصادر الطاقة. تشجيع التعاون و التبادل العلمي مع الدول المتقدمة والاستفادة من خبر اتها من خلال عقد اللقاءات والندوات الدورية حيث يكون ذلك على أساس المساو اة و المنفعة المنبادلة. -لا يمكن البدء بتطوير مشروعات الطاقة المتجدة على أسس صحيحة دون هيكلة حقيقية وصحيحة للجهات المعنية وتطوير آليات قانونية وأكثر مرونة. ـالعمل على نشر الوعي وتقديم الحو افز لتشجيع اعتماد تكنولوجيا وممارسات كفاءة الطاقة والطاقة المتجددة. 


\section{قائمة المصادر والمراجع:}

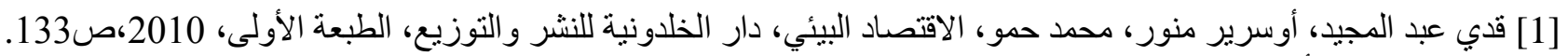

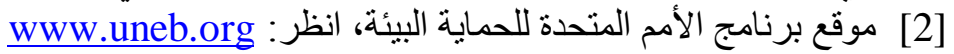

[3] Renewable Energy : Technologies ucsusa.org

[4] برنامج الأمم المتحدة الإنمائي، الدليل الإرشادي للبرلمانيين من أجل الطاقة المتجدةة، واشنطن، 2013، ص ص 33-34.

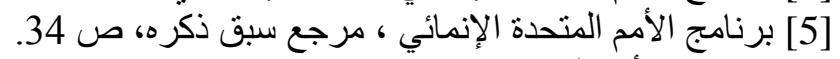

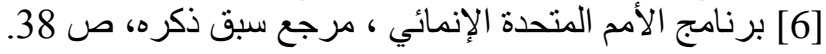

[7] Renewable Energy, nrdc.org, op-cit.

[8] الخياط محمد مصطفى ، الطاقة البديلة تحديات و آمال، مجلة السياسة الدولية، العدد 164، المجلد 41، 2006، ص6أنة.

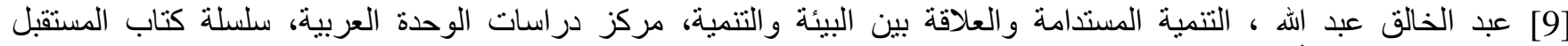

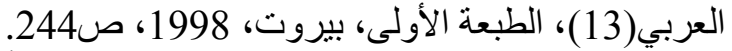

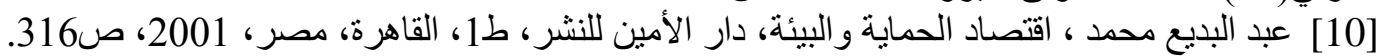
[11] وديع محمد عدنان، قياس التنمية ومؤشراتها، مجلة جسر التنمية، المجلد الأول، العدد الثاني، منشورات التهات المعهد العربي للتخطيط

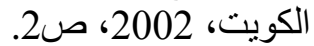

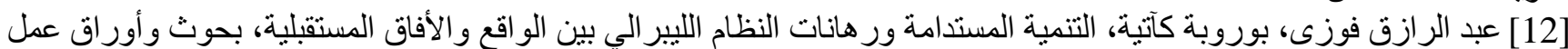

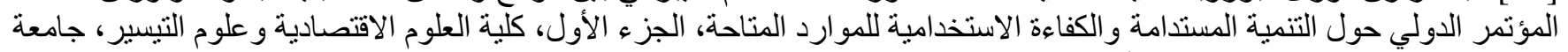

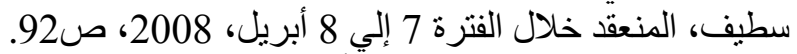
[13] عثمان محمد غنيم، ماجدة أبو زنطة، التئ، التنمية المستدامة فلسفتها وأساليب تخطيطها وأدوات قياسها، دار الصفا للنشر والتوزيع،

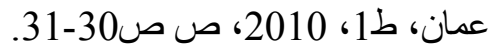

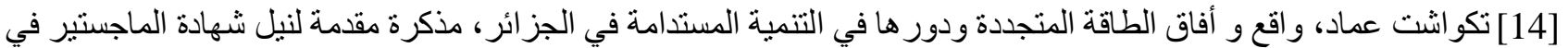

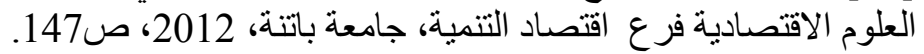
[15] سمير بلعربي، واقع طاقة الرياح في الجزائر، البوابة الجزائرية للطاقات المتجددة، انظر: http://portail.cder.dz/ar/spip.php?article1464 .2019/11/03

[16] وز ارة الطاقة و المناجم، دليل الطاقات المتجددة، 2007، ص420ê. [17] AKBI Amine, La bioénergie en Algérie: Un gisement important, et des bénéfices environnementaux, http://www.cder.dz/vlib/bulletin/pdf/ber33_4_5.pd, 03/11/2019

[18] لجنة ضبط الكهرباء و الغاز CREG، تقديم لبرنامج تطوير الطاقات الجديدة والمتجددة والنجاعة الطاقوية، مارس/2011، ص3/203.

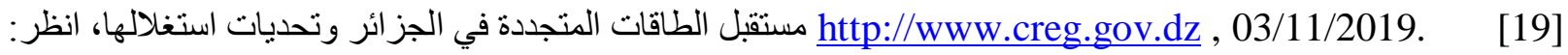
https://portail.cder.dz 03/11/2019

[20] محطة جديدة تنتج قر ابة 300 ميغاو اط الحكومة تحل أزمة انقطاع الكهرباء في الصيف بالطاقات المتجدة، انظر : http://www.al-fadjr.com/ar/economie/328134.html11 04/11/2019

[21] زواوية أحلام، دور اقتصاديات الطاقات المتجددة في تحقيق التنمية الاقتصادية المستدامة في الدول المغاربية، دراسة مقارنة بين الجز ائر المغرب و تونس، مذكرة مقدمة كجزء من منطلبات نيل شهادة الماجستير في إطار مدرسة الدكتور اه في العلوم الاقتصادية وعلوم

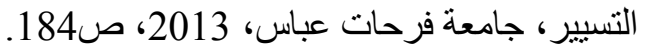
[23] قطاع الطاقات المتجدة في الجزائر ، انظر : http://www.andi.dz/index.php/ar/les-energies-renouvelables 04/11/2019

$$
\text { تكثوات عماد، مرجع سبق ذكره، ص ص 173- } 174 .
$$

